\title{
ИЗУЧЕНИЕ ЭКВИВАЛЕНТНОСТИ БИОСИМИЛЯРА ИНСУЛИНА АСПАРТ ДВУХФАЗНЫЙ В СРАВНЕНИИ С ЗАРЕГИСТРИРОВАННЫМ АНАЛОГОМ С ИСПОЛЬЗОВАНИЕМ МЕТОДА ГИПЕРИНСУЛИНЕМИЧЕСКОГО ЭУГЛИКЕМИЧЕСКОГО КЛЭМПА У ЗДОРОВЫХ ДОБРОВОЛЬЦЕВ
}

\author{
'Майоров А.Ю., ${ }^{2}$ Каронова Т.Л., 'Кокшарова Е.О., ${ }^{3}$ Драй Р.В. \\ ${ }^{1}$ ФГБУ «НМИЦ эндокринологии» Минздрава России, Москва \\ ${ }^{2}$ ФГБУ «Национальный медицинский исследовательский центр имени В.А. Алмазова» Минздрава России, \\ Санкт-Петербург

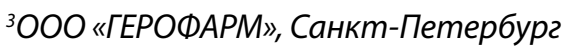

Программа разработки биосимиляров аналогов инсулинов представляет собой сложный, многостадийный, строго регламентированный процесс, одним из ключевых этапов которого является изучение фармакокинетических (ФК) и фармакодинамических (ФД) свойств тестируемого препарата в условиях клинического исследования.

ЦЕЛЬ: сравнительная оценка ФК и ФД показателей двух препаратов, содержащих инсулин аспарт двухфазный: оригинального препарата и воспроизведенного биосимиляра отечественного производства.

МАТЕРИАЛЫ И МЕТОДЫ: данное исследование было проведено как рандомизированное сравнительное перекрестное с двумя периодами двойное слепое с использованием метода эугликемического гиперинсулинемического клэмпа с участием 34 здоровых добровольцев. Клэмп исследование является золотым стандартом исследования инсулинов, поскольку после однократной инъекции инсулина позволяет одновременно оценить фармакодинамические (ФД) и фармакокинетические (ФК) показатели. ФД показатели определяют по способности инсулина снижать уровень глюкозы плазмы крови. При этом, чтобы не подвергать участников исследования гипогликемии, в ответ на снижение уровня глюкозы, проводят внутривенное введение глюкозы с определенной скоростью. По мере усиления действия инсулина (вплоть до достижения пика) скорость инфузии глюкозы (GIR) увеличивается. ФК показатели определяют по концентрации инсулина в крови. В рамках проведенного исследования препарат вводили в дозе 0,4 ЕД/кг однократно подкожно в область передней брюшной стенки живота. К основным ФД показателям относили площадь под кривой скорости инфузии глюкозы-время (AUC GIRo-t $_{\text {) }}$ и максимальной скорости инфузии глюкозы (GIR $\left.{ }_{\text {max }}\right)$. В качестве ФК показателей производили оценку площади под кривой концентрации инсулина-время (AUC ins.o-t $\left._{\text {. }}\right)$ и максимальной концентрации инсулина $\left(C_{\text {ins.max }}\right)$. Следует отметить, что согласно международным нормам и Российскому законодательству, если из одной активной фармацевтической субстанции (АФС) разрабатывается два инсулиновых продукта (например, аспарт раствор и аспарт микс), для оценки сопоставимости второго продукта допускается подтверждение только ФК показатели. В то время как ФД свойства, зависящие от АФС, уже подтверждены на первом продукте. Различия между раствором и миксом заключаются в ФК показателях между, оригинальном и исследуемым препаратами.

РЕЗУЛЬТАТЫ: доверительные интервалы основных ФК показателей, $A U C_{\text {ins.0-т и }} C_{\text {ins.max }}$ составили 95 [82.90-109.50]\% и 98 [89.20-108.03]\% соответственно. Оба показателя соответствовали допустимым пределам (80.00-125.00\%). Также, в исследовании была оценена межиндивидуальная вариабельность ФК и ФД показателей, которая для $A \cup C_{\text {ins.o- }}$ составила 43.6 и 52.0\%, а для $C_{\text {ins.max }}-33.5$ и 40.3\% для биосимиляра и оригинального препарата соответственно. Сопоставимые данные были получены в отношении межиндивидуальной вариабельности ФД показателей: для $\mathrm{AUC}_{\mathrm{GIR0-t}}-43.0$ и $46.0 \%$, для $\mathrm{GIR}_{\max }-43.0$ и $45.0 \%$ для биосимиляра и оригинального препарата соответственно.

Выводы: по результатам проведенного исследования была подтверждена полная биосимилярность воспроизведенного аналога инсулина аспарт двухфазный оригинальному препарату с отсутствием межиндивидуальной вариабельности воспроизведенного аналога по сравнению с оригинальным препаратом. 